\title{
Effect of fuel type on the combustion reaction behavior, phase structure and morphology of $\mathrm{Ni}_{0.5} \mathrm{Co}_{0.5} \mathrm{Fe}_{2} \mathrm{O}_{4}$ nanoparticles
}

\author{
Arman Sedghi*, Elham AKbari SalehKooh, Monireh ChadorbafZade \\ Materials Engineering Department, Imam Khomeini International University, Qazvin 34149-16818, Iran
}

\begin{abstract}
Nickel-cobalt ferrite spinels are ferrimagnetic ceramic materials that possess a great potential for application in highdensity magnetic media, recording, color imaging, ferrofluids, and high-frequency devices. A change of their structure from micro- to nano- improves their properties drastically, therefore many methods have been investigated to fabricate nanopowder of these spinels. Gel combustion method is one of them. In this research, $\mathrm{Ni}_{0.5} \mathrm{Co}_{0.5} \mathrm{Fe}_{2} \mathrm{O}_{4}$ nanoparticles were fabricated via gel combustion method using metallic nitrates as an oxidant and citric acid, glycine and urea as fuels and the effects of fuel type on the reaction behavior, structure and morphology of $\mathrm{Ni}_{0.5} \mathrm{Co}_{0.5} \mathrm{Fe}_{2} \mathrm{O}_{4}$ nanoparticles were investigated. The reaction behavior was studied by thermal analysis method (TGA-DTA), crystallite size of powders was characterized by X-ray diffraction (XRD) and their morphology was studied by FE-SEM. The results revealed that the reaction was initiated in urea, glycine and citric at $219^{\circ} \mathrm{C}, 197^{\circ} \mathrm{C}, 212^{\circ} \mathrm{C}$, respectively. Samples fabricated from glycine and citric acid had a pure spinel structure but the others fabricated with urea fuel had iron oxide impurity. The crystallite size of nickel cobalt ferrite nanoparticles was in the range of $58 \mathrm{~nm}$ to $64 \mathrm{~nm}$ and the nanoparticles were agglomerated.
\end{abstract}

Keywords: nickel cobalt ferrite; nanoparticles; glycine; urea; citric acid; gel combustion

\section{Introduction}

Spinel ferrites are ferromagnetic ceramic materials that possess a great potential for application in high-density magnetic media, recording, color imaging, ferrofluids, high-frequency devices, magnetic refrigeration, heterogeneous catalysis, magnetic resonance imaging, gas sensors, high quality ceramics and drug delivery systems [1-7].

Spinel ferrites have the general molecular formula $\mathrm{AB}_{2} \mathrm{O}_{4}$, in which $\mathrm{A}^{2+}$ and $\mathrm{B}^{3+}$ occupy in the FCC lattice formed by oxygen anions, tetrahedral and octahedral sites, respectively. The interesting and useful magnetic properties of spinel ferrites depend on the choice of cations along with $\mathrm{Fe}^{2+}$ and $\mathrm{Fe}^{3+}$ ions and their distribution between tetrahedral (A) and octahedral (B) sites of the spinel lattice. One of the most important ferrite spinel is nickelcobalt ferrite spinel which has a great potential for many of these applications $[1,2,5,7]$.

A change in their structure from micro to nano improves the nickel-cobalt ferrite spinel

*E-mail: sedghi@eng.ikiu.ac.ir properties drastically, therefore many methods have been investigated to fabricate nanopowder nickel-cobalt ferrite spinel, including mechanical alloying [13, 25, 27], co-precipitation [6, 11], solgel [15], autocatalytic decomposition of precursor [19], aerosol route [14], calcination of cosubstituted $\mathrm{NiFe}^{2+} \mathrm{Fe}^{3+}$-layered double hydroxide $\left(\mathrm{NiFe}^{2+} \mathrm{Fe}^{3+}-\mathrm{LDH}\right)$ precursors [2], combination of sol-gel process and in-situ polymerization [4] and combustion reactions [17-22]. Although Ni-Co ferrites are produced by solid state reaction, owing to the low activity of reactants in the traditional dry methods, the reaction may not reach completion, and even some impurities may remain in the final products [2]. On the other hand, the particles obtained by this process are rather large and non-uniform in size [3]. In the case of wet methods, the precipitating agent introduced in the coprecipitation or the ligands of the precursors used in sol-gel methods cannot be easily completely removed, leading to adverse effect on the purity and performance of the final products [2]. Instead, combustion reaction synthesis has been used successfully to obtain powders with nanosized particles 
$(<100 \mathrm{~nm})$ and large surface areas. This method of synthesis is advantageous due to its simplicity, short reaction time from the preparation of reagents to the end product, elimination of intermediary calcination stages, and lower consumption of energy during synthesis $[17,21]$. This process involves an exothermic and self-sustaining chemical reaction between the metal salts and suitable fuels, usually urea [16, 17, 21, 23, 24], glycine [5, 10, 16, 17], sucrose [12], DL-alanine [18], hydrazides [16] and citric acid [1, 7-9, 22]. During the combustion, exothermic redox reactions associated with nitrate decomposition and fuel oxidation take place. Gases such as $\mathrm{N}_{2}, \mathrm{H}_{2} \mathrm{O}$, and $\mathrm{CO}_{2}$ evolve, favoring the formation of fine particle ashes after only a few minutes [20].

The powder characteristics, like crystallite size, surface area, extent and nature of agglomeration are primarily governed by enthalpy or flame temperature generated during combustion, which itself is dependent on the nature of the fuel $[16,20]$. Therefore, the objective of this study was to investigate the effect of variation of fuel on the synthesis of Co-Ni ferrites by gel combustion method, and to evaluate their morphology and magnetic properties.

\section{Experimental}

Analytical grade nickel nitrate, iron nitrate, cobalt nitrate and fuels (citric acid, glycine and urea) all from Scharlau Company were used as raw materials to prepare Ni-Co ferrite nanoparticles.

According to propellant chemistry, in case of ferrites, the oxidizing valence of a divalent metal nitrate $\mathrm{M}\left(\mathrm{NO}_{3}\right)_{2}$ becomes generally -10 , and that for trivalent metal nitrate $\mathrm{M}\left(\mathrm{NO}_{3}\right)_{3}$ becomes -15 , which should be balanced by total reducing valences of fuels such as citric acid, glycine and urea, which add up to $+18,+9,+6$, respectively. Hence, in order to release maximum energy, the stoichiometric composition of redox mixture for the reaction requires 2.22 mole of citric acid, 4.44 mole of glycine and 6.66 mole of urea [10, 18, 23, 24]. These assumptions lead to reaction 1 to 3 for fabrication of nickel-cobalt ferrite from citric acid, glycine and urea fuels, respectively:

\section{for citric acid:}

$$
\begin{aligned}
& 0.5 \mathrm{Co}\left(\mathrm{NO}_{3}\right)_{2} \cdot 6 \mathrm{H}_{2} \mathrm{O}+0.5 \mathrm{Ni}\left(\mathrm{NO}_{3}\right)_{2} \cdot 6 \mathrm{H}_{2} \mathrm{O} \\
& +2 \mathrm{Fe}\left(\mathrm{NO}_{3}\right)_{3} \cdot 9 \mathrm{H}_{2} \mathrm{O}+2.22 \Phi \mathrm{C}_{6} \mathrm{H}_{8} \mathrm{O}_{7} \cdot \mathrm{H}_{2} \mathrm{O} \\
& +(9.99 \Phi-10) \mathrm{O}_{2(g)} \rightarrow \mathrm{Ni}_{0.5} \mathrm{Co}_{0.5} \mathrm{Fe}_{2} \mathrm{O}_{4} \\
& +13.32 \Phi \mathrm{CO}_{2(\mathrm{~g})}+(24+11.1 \Phi) \mathrm{H}_{2} \mathrm{O}_{(\mathrm{g})}+4 \mathrm{~N}_{2(g)}
\end{aligned}
$$

\section{for glycine:}

$$
\begin{aligned}
& 0.5 \mathrm{Co}\left(\mathrm{NO}_{3}\right)_{2} \cdot 6 \mathrm{H}_{2} \mathrm{O}+0.5 \mathrm{Ni}\left(\mathrm{NO}_{3}\right)_{2} \cdot 6 \mathrm{H}_{2} \mathrm{O} \\
& +2 \mathrm{Fe}\left(\mathrm{NO}_{3}\right)_{3} \cdot 9 \mathrm{H}_{2} \mathrm{O}+4.44 \Phi \mathrm{NH}_{2} \mathrm{CH}_{2} \mathrm{COOH} \\
& +(9.99 \Phi-10) \mathrm{O}_{2(g)} \rightarrow \mathrm{Ni}_{0.5} \mathrm{Co}_{0.5} \mathrm{Fe}_{2} \mathrm{O}_{4} \\
& +8.88 \Phi \mathrm{CO}_{2(g)}+(24+11.1 \Phi) \mathrm{H}_{2} \mathrm{O}_{(g)} \\
& +(4+2.22 \Phi) \mathrm{N}_{2(g)}
\end{aligned}
$$

\section{for urea:}

$$
\begin{aligned}
& 0.5 \mathrm{Co}\left(\mathrm{NO}_{3}\right)_{2} \cdot 6 \mathrm{H}_{2} \mathrm{O}+0.5 \mathrm{Ni}\left(\mathrm{NO}_{3}\right)_{2} \cdot 6 \mathrm{H}_{2} \mathrm{O} \\
& +2 \mathrm{Fe}\left(\mathrm{NO}_{3}\right)_{3} \cdot 9 \mathrm{H}_{2} \mathrm{O}+6.66 \Phi\left(\mathrm{NH}_{2}\right)_{2} \mathrm{CO} \\
& +(9.99 \Phi-10) \mathrm{O}_{2(g)} \rightarrow \mathrm{Ni}_{0.5} \mathrm{Co}_{0.5} \mathrm{Fe}_{2} \mathrm{O}_{4} \\
& +6.66 \Phi \mathrm{CO}_{2(g)}+(24+13.32 \Phi) \mathrm{H}_{2} \mathrm{O}_{(\mathrm{g})} \\
& +(4+6.66 \Phi) \mathrm{N}_{2(\mathrm{~g})}
\end{aligned}
$$

where, $\Phi$ is the multiplication factor; to get the fuel lean $(\Phi<1)$, fuel stoichiometric $(\Phi=1)$, and fuel rich condition $(\Phi>1)$.

In a typical procedure, stoichiometric amounts of the materials were put into a glass beaker and dissolved in distiled water. Then, a small amount of ammonia was added into the solution to adjust the $\mathrm{pH}$ value to about 7 and stabilize the nitratecitrate solution. During this procedure, the solution was continuously stirred using a magnetic agitator and kept at a temperature of $70{ }^{\circ} \mathrm{C}$. After that, the mixed solution was poured into a dish, heated slowly to $135{ }^{\circ} \mathrm{C}$ and stirred constantly until the viscosity and color changed as the solution turned in to a brown porous dry gel. When the temperature was increased, the dried gel simultaneously burnt in a self-propagating combustion manner until all the gel was completely burnt out to form a loose powder. The as-synthesized powder was then calcined at $1000{ }^{\circ} \mathrm{C}$ for $1 \mathrm{~h}$. The flow chart of the fabrication process is shown in Fig. 1. 


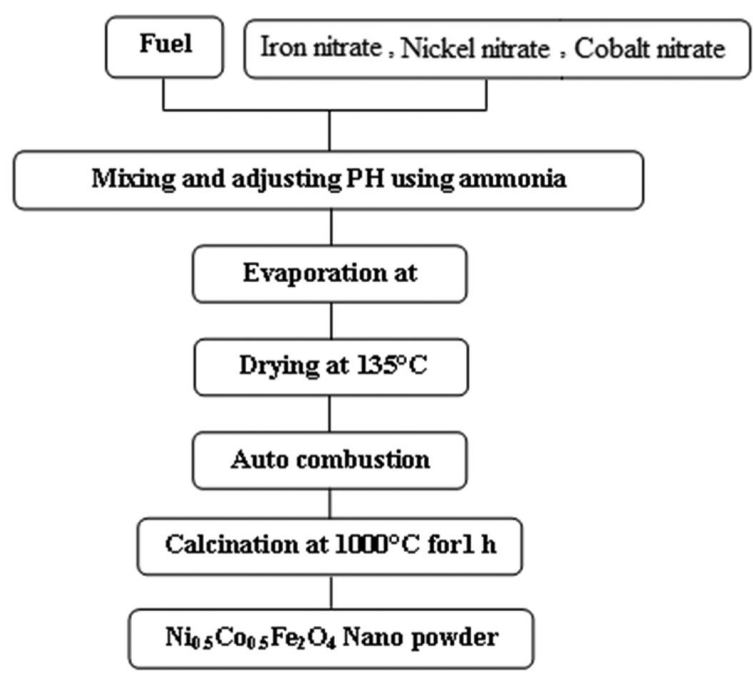

Fig. 1. Flow chart for preparing nanosized ferrite powders by gel auto-combustion method.

Phase structure was characterized by X-ray diffraction (Philips PW3040/60) with $\mathrm{CuK} \alpha$ radiation $(0.15406 \mathrm{~nm})$. The results were compared with JCPDS standard pattern (No. 52-278). The magnetization measurements on the samples were carried out by using a vibrating sample magnetometer (VSM; Model 7307, Lake Shore Cryotronics, Westerville, $\mathrm{OH}$ ), at a maximum applied field of $1 \mathrm{kOe}$. From the obtained hysteresis loops, the saturation magnetization $\left(\mathrm{M}_{\mathrm{s}}\right)$, remnant magnetization $\left(\mathrm{M}_{\mathrm{r}}\right)$ and coercivity $\left(\mathrm{H}_{\mathrm{c}}\right)$ were estimated. The morphology of the particles was analyzed by scanning electron microscope (FE-SEM Hitachi S-4160, Japan). The samples were dispersed in ethanol, then treated ultrasonically in order to disperse individual particles and coated with gold using sputtering method before study. The dried gel precursors were characterized via thermogravimetric (TGA) and differential thermal analysis (DTA) (Pyris Diamond TGA/ DTA, Perkin Elmer Company) in temperature range of $25-1000{ }^{\circ} \mathrm{C}$ at a heating rate of $10{ }^{\circ} \mathrm{C} / \mathrm{min}$ in argon ambience.

\section{Results and discussion}

\subsection{Thermodynamic investigation}

In order to study the thermodynamic behavior of combustion reaction involving different fuel to nitrate ratios, a simplified thermodynamic approach has been employed. Adiabatic flame temperature $T_{a d}$ was used to define the temperature at which the enthalpies of the products are equal to those of reactants. If all heat generated heats up the product and no heat exchange takes place with the surroundings, then $\mathrm{T}_{\mathrm{ad}}$ can be calculated using the following equations [26].

$$
Q=-\Delta H=\int_{298}^{T_{a d}}\left(\sum n \cdot C_{P}\right)_{\text {products }} \cdot d T
$$

where, is the number of moles, $\mathrm{Q}$ is the heat absorbed by products under adiabatic condition, and $\mathrm{Cp}$ is the heat capacity of the products at a constant pressure. For adiabatic calculations, room temperature was considered as reference, $\mathrm{T}_{\mathrm{O}}=298 \mathrm{~K}$. The change in enthalpy of reaction $\left(\Delta \mathrm{H}^{\circ}\right)$ can be expressed as:

$$
\Delta H=\sum n\left(\Delta H_{f}^{\circ}\right)_{\text {products }}-\sum n\left(\Delta H_{f}\right)_{\text {reactants }}
$$

where $\mathrm{n}$ is the number of moles and $\Delta \mathrm{H}_{\mathrm{f}}^{\circ}$ is the enthalpy of formation.

So when the ignition process occurs rapidly it can be considered as an adiabatic processes. By using thermodynamic data from Table 1 and equations 4 and 5, adiabatic flame temperature $\left(\mathrm{T}_{\mathrm{ad}}\right)$ for various $\Phi$ values can be calculated and thermodynamic parameters of combustion can be compared. The enthalpy of $\mathrm{CoFe}_{2} \mathrm{O}_{4}$ combustion with citric acid, glycine and urea have been obtained and shown in equation 6 to 8 for citric acid, glycine and urea, respectively:

$$
\begin{gathered}
\Delta H_{\text {citric acid }}^{\circ}=460+\Phi(-919.2) \\
\Delta H_{\text {Glycine }}^{\circ}=459.93+\Phi(-1122.71) \\
\Delta H_{\text {Urea }}^{\circ}=459.93+\Phi(-865.46)
\end{gathered}
$$

For calculation of the results, $\Phi=1$ has been assumed, the reactions were performed in adiabatic conditions, room temperature was considered as reference, $\mathrm{T}_{\mathrm{O}}=298 \mathrm{~K}$ and based on these, the change in enthalpy of reaction $\left(\Delta \mathrm{H}^{\circ}\right)$, adiabatic flame temperature $\mathrm{T}_{\mathrm{ad}}$ and amount 
Table 1. Thermodynamic data required for calculating adiabatic flame temperature [26].

\begin{tabular}{ccc}
\hline Compound & $\mathrm{H}_{\mathrm{f}}\left(\mathrm{kcal} \cdot \mathrm{mol}^{-1}\right)$ & $\mathrm{C}_{\mathrm{p}}\left(\mathrm{cal} \mathrm{mol}^{-1} \mathrm{~K}^{-1}\right)$ \\
\hline \hline $\mathrm{Co}\left(\mathrm{NO}_{3}\right)_{2} \cdot 6 \mathrm{H}_{2} \mathrm{O}$ & -528.49 & - \\
$\mathrm{Fe}\left(\mathrm{NO}_{3}\right)_{2} \cdot 9 \mathrm{H}_{2} \mathrm{O}$ & -785.2 & - \\
$\mathrm{H}_{2} \mathrm{O}[\mathrm{g}]$ & -58.79 & $7.2+0.0036 \mathrm{~T}$ \\
$\mathrm{O}_{2}[\mathrm{~g}]$ & 0 & $5.92+0.00367 \mathrm{~T}$ \\
$\mathrm{CoFe}_{2} \mathrm{O}_{4}$ & -252.0 & $10.34+0.00274 \mathrm{~T}$ \\
$\mathrm{CO}_{2}[\mathrm{~g}]$ & -94.05 & 35.36 \\
$\mathrm{~N}_{2}$ & 0 & $6.5+0.001 \mathrm{~T}$ \\
\hline
\end{tabular}

Table 2. Comparison of enthalpy of reaction $\left(\Delta \mathrm{H}^{\circ}\right)$, adiabatic flame temperature $\mathrm{T}_{\mathrm{ad}}$ and amount of gases produced during combustion between $\mathrm{Ni}_{0.5} \mathrm{Co}_{0.5} \mathrm{Fe}_{2} \mathrm{O}_{4}$ synthesized with citric acid, glycine and urea as a fuel.

\begin{tabular}{cccc}
\hline Fuel & $\Delta \mathrm{H}^{\circ}[\mathrm{kcal} / \mathrm{mol}]$ & $\mathrm{T}_{\mathrm{ad}}[\mathrm{K}]$ & $\begin{array}{c}\text { Amount of gases produced during combustion } \\
\text { (moles) }\end{array}$ \\
\hline \hline Citric acid & -458.31 & 715.61 & 52.42 \\
Glycine & -662.78 & 1219.87 & 50.2 \\
Urea & -405.53 & 901.47 & 54.64 \\
\hline
\end{tabular}

of gases produced during combustion between $\mathrm{Ni}_{0.5} \mathrm{Co}_{0.5} \mathrm{Fe}_{2} \mathrm{O}_{4}$ synthesized with citric acid, glycine and urea as a fuel were calculated and are shown in Table 2.

Thermal analysis The simultaneous TG-DTA curves of the stoichiometric metal nitrates with citric acid, glycine and urea (fuel) are shown in Fig. 2, Fig. 3 and Fig. 4, respectively. In the TGA curves of all the samples, sharp weight loss steps can be observed. This weight loss is about $85 \%$ for samples prepared with citric acid and about $90 \%$ for samples synthesized with glycine and urea which is associated with the exothermic processes due to decomposition of the polymeric precursor during the combustion. According to the DTA curves, it is observed that there is a strong and sharp exothermic peak at $\sim 212{ }^{\circ}$ for citric acid fuel. It is also observed an almost so strong peak at $\sim 197^{\circ}$ for glycine fuel while for urea there is a smooth and weak peak at $\sim 219^{\circ}$. So urea may not produce enough combustion energy for reaction.

From these experimental studies it can be suggested that the samples synthesized with urea as a fuel cannot heat rapidly at/or above the temperature of exothermic decomposition of fuel, so the mixture burns without flame. In contrast, citric acid and glycine can afford heat required for ignition with flame and at such high in situ temperature, the foam decomposes to maximum yield product.

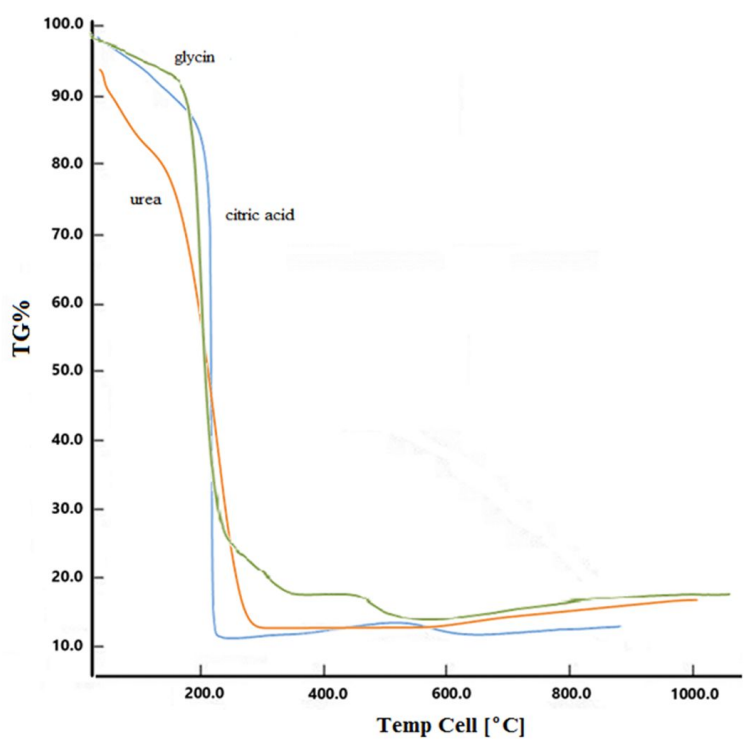

Fig. 2. TG curves of $\mathrm{Ni}_{0.5} \mathrm{Co}_{0.5} \mathrm{Fe}_{2} \mathrm{O}_{4}$ synthesized with citric acid, glycine and urea fuel

Phase analysis and particle size Fig. 5 shows the X-ray diffraction patterns of $\mathrm{Ni}_{0.5} \mathrm{Co}_{0.5} \mathrm{Fe}_{2} \mathrm{O}_{4}$ nanopowders synthesized at stoichiometric ratio of 


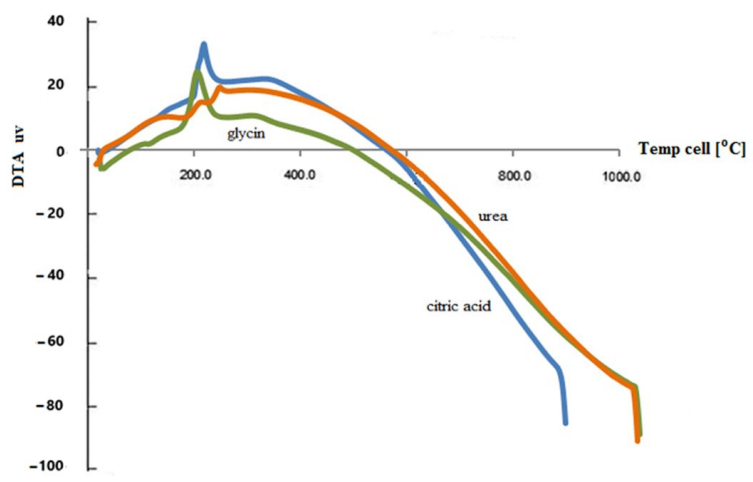

Fig. 3. DTA curves of $\mathrm{Ni}_{0.5} \mathrm{Co}_{0.5} \mathrm{Fe}_{2} \mathrm{O}_{4}$ synthesized with citric acid, glycine and urea fuel

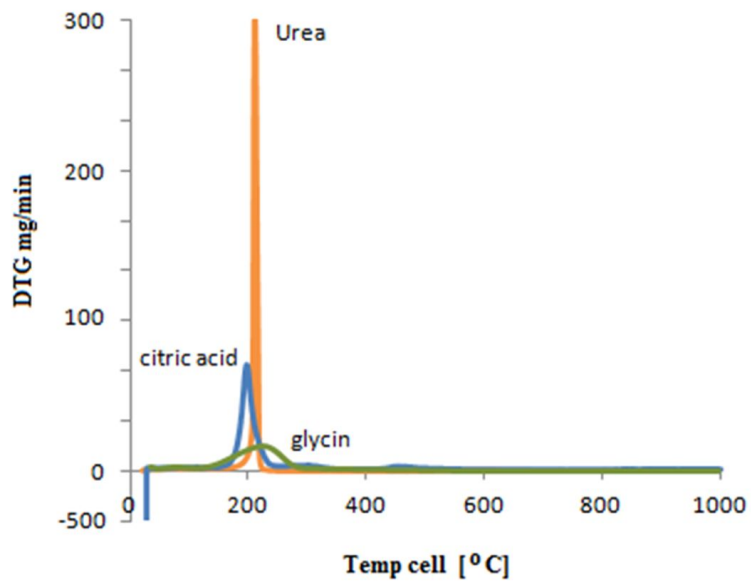

Fig. 4. DTG curves of $\mathrm{Ni}_{0.5} \mathrm{Co}_{0.5} \mathrm{Fe}_{2} \mathrm{O}_{4}$ synthesized with citric acid, glycine and urea fuel

citric acid, glycine and urea as a fuel. Based on JCPDS card number 52-278, the nanopowders exhibit typical diffraction of ( $\left.\begin{array}{lll}1 & 1 & 1\end{array}\right),\left(\begin{array}{lll}2 & 2 & 0\end{array}\right),\left(\begin{array}{lll}3 & 1 & 1\end{array}\right)$, (2 2 2), (4 0 0 $)$ ), (4 2 2 2), (5 11 1), (4 4 0 0 ) planes which are related to cubic spinel structure. The strong and sharp diffraction peaks indicate the high crystallinity of the samples. No secondary peaks have been detected in the XRD patterns of the samples that were synthesized with citric acid and glycine which confirms the phase purity of the samples. But the pattern also shows the trace amount of secondary hematite in the sample synthesized with urea.

Formation of secondary hematite in the sample synthesized with urea has also been observed when Costa et. al. [17] synthesized ferrite ( $\mathrm{Mn}, \mathrm{Zn}) \mathrm{Fe}_{2} \mathrm{O}_{4}$ via sol gel autocombustion. The sample synthesized with glycine showed the formation of a highly crystalline monophasic powder (formation of ferrite $\mathrm{Mn}-\mathrm{Zn}$ phase only). The crystallite and particle sizes, determined by BET, were 18 and $35 \mathrm{~nm}$, respectively, for the powders synthesized with urea fuel, and 18 and $193 \mathrm{~nm}$ for those synthesized with glycine fuel.

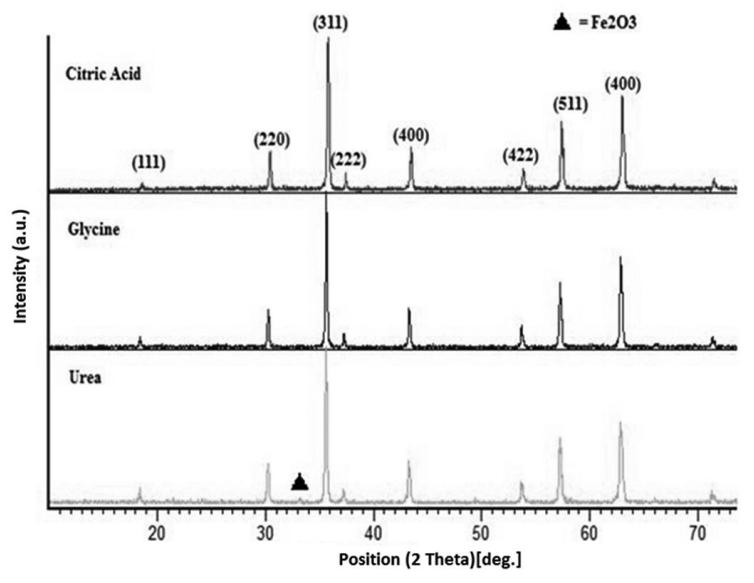

Fig. 5. X-ray diffraction patterns of $\mathrm{Ni}_{0.5} \mathrm{Co}_{0.5} \mathrm{Fe}_{2} \mathrm{O}_{4}$ nanopowders synthesized by citric acid, glycine and urea fuels

The resultant nano-scaled crystallite size of the samples is due to two characteristics of the reaction system. One is that the reactants have been uniformly dispersed at an atomic or molecular level before reaction, so when ignition occurred, the nucleation process could be completed only by the rearrangement and short-distance diffusion of nearby atoms. The other is that the rate of combustion reaction is so high that enough time and energy can not be provided for the long-distance diffusion of atoms and the obvious growth of the crystallites, as a result of which, the initial nanophase is retained [16].

The average crystallite size is obtained using Scherrer equation where $\mathrm{D}$ is a crystallite size [nm], $\beta(2 \theta)$ is full width at half maximum of the diffraction peak that is calculated with equation $10, \lambda$ is the wavelength of $\mathrm{X}$-ray (here $0.1541 \mathrm{~nm}$ ), $\theta$ is Bragg angle and $\mathrm{K}$ is the Scherrer constant.

$$
D=\frac{K \lambda}{\beta(2 \theta) \cos \theta}
$$




$$
\beta(2 \theta)=\left(\beta_{\text {exp }}^{2}-\beta_{\text {instr }}^{2}\right)^{\frac{1}{2}}
$$

In equation $10, \beta_{\exp }$ is a peak width at half height for the major peaks detected by $\mathrm{X}$ ray diffraction of the samples, $\beta_{\text {instr }}$ is instrumental broadening equal to about $0.02 \mathrm{rad}$ in our instrument. The average crystallite size of $\mathrm{Ni}_{0.5} \mathrm{Co}_{0.5} \mathrm{Fe}_{2} \mathrm{O}_{4}$ nanopowders synthesized with citric acid, glycine and urea as a fuel in $\Phi=1$ is given in Table 3.

Morphology of nanopowders Typical SEM pictures of products from the various fuels are shown in Fig. 6. The samples exhibit large and homogeneous particles in the range of $200-300 \mathrm{~nm}$. The larger size of the nanoparticles compared to the values given from the Scherrer formula may be caused by their agglomeration as well as magnetic dipole interaction among them. This feature is mainly attributed to the combustion flame temperature and reaction time during the synthesis of these nanopowders. All the calcined powders show characteristic porous features due to the release of large amounts of gases during combustion.

The particles exhibit a network with voids and pores typical of combustion-synthesized powders. The porous powders are highly friable which facilitates their grinding to finer particles [22]. As it was expected from thermodynamic calculations and thermal analysis results, the nanoparticles that were synthesized with glycine fuel are finer and more homogenous than those synthesized from citric acid.

Comparison of Fig. 6a with Fig. $6 \mathrm{~b}$ also shows that the nanopowders which were synthesized with citric acid are more porous. It may be related to gaseous products during combustion reaction which have been presented in Table 2. The amount of such products in the samples synthesized with glycine fuel is less than in the others. It is also visible in Fig. 6c, that the nanoparticles which were synthesized with urea fuel are denser and larger than in other samples. It can be suggested that slow combustion process leads to such a large and dense morphology.

It was also seen from previous studies [23], when the reaction is slower and the release of gases is gradual, fabricated samples have more porous
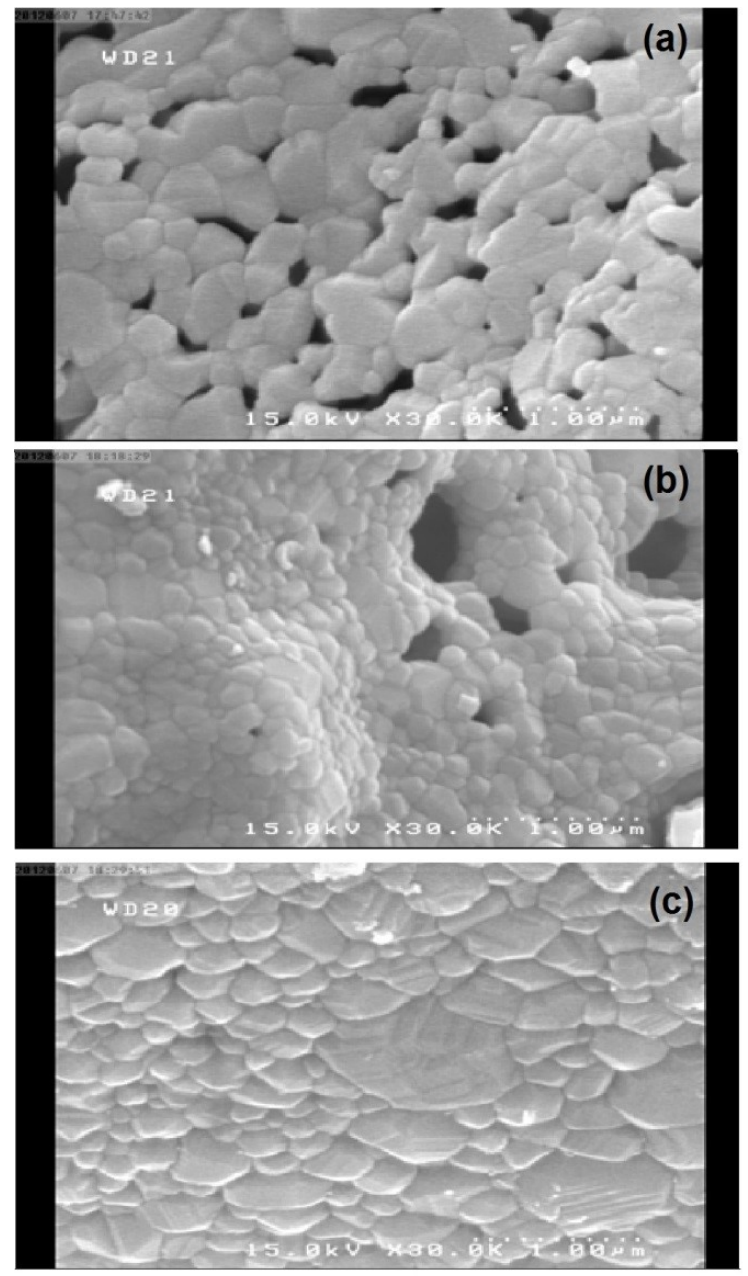

Fig. 6. SEM images of $\mathrm{Ni}_{0.5} \mathrm{Co}_{0.5} \mathrm{Fe}_{2} \mathrm{O}_{4}$ nanopowders synthesized with (a) citric acid (b) glycine and (c) urea fuels

structure with smaller nanoparticles size. This feature is visible in the SEM images of the samples that were synthesized with urea fuel. On the other hand, it can be seen that the morphology of the particles synthesized with this fuel has relatively larger agglomerates than two other fuels. Spherical and irregular shaped particles with the wide particle size distribution, correspond to the results presented by Costa et al. [24]. Of course, agglomerates sizes calculated from the SEM images are much less than those obtained from the previous combustion synthesis of $\mathrm{NiFe}_{2} \mathrm{O}_{4}$ nanopowders with urea fuel [24]. This probably is related to the different nanopowder fabrication routine in our study. 
Table 3. Comparison of crystallite size of $\mathrm{Ni}_{0.5} \mathrm{Co}_{0.5} \mathrm{Fe}_{2} \mathrm{O}_{4}$ nanopowders synthesized with citric acid, glycine and urea fuels calculated from different planes XRD peaks

\begin{tabular}{|c|c|c|c|}
\hline Fuels & \multicolumn{3}{|c|}{ Crystallite size } \\
\hline & $\mathrm{D}_{(311)}[\mathrm{nm}]$ & $\mathrm{D}_{(400)}[\mathrm{nm}]$ & $\mathrm{D}_{(511)}[\mathrm{nm}]$ \\
\hline Citric acid & 48.56 & 81.27 & 79.01 \\
\hline Glycine & 52.8 & 61.22 & 72.96 \\
\hline Urea & 54.63 & 75.3 & 80.57 \\
\hline
\end{tabular}

Magnetic properties Magnetic properties of cobalt-nickel ferrite nanopowders were studied by using the VSM technique. Magnetic hysteresis loops of the samples at room temperature are shown in Fig. 7. As it observed in this figure, the synthesized nanopowders show ferromagnetism that originates from magnetic moment of antiparallel spins between $\mathrm{Fe}^{3+}$ ions at octahedral sites and $\mathrm{Co}^{2+}, \mathrm{Ni}^{2+}$ ions at tetrahedral sites of an inverse spinel structure [26]. The coercivity $\left(\mathrm{H}_{c}\right)$, saturation magnetization $\left(\mathrm{M}_{s}\right)$, remnant magnetization $\left(\mathrm{M}_{r}\right)$, and $\mathrm{M}_{r} / \mathrm{M}_{s}$ ratio for the samples synthesized with different fuels are summarized in Table 4 .

From Table 4, it is obvious that the value of $\mathrm{H}_{\mathrm{c}}$ is 300 Oe for all of three samples. This result indicates that coercivity of $\mathrm{Co}_{0.5} \mathrm{Ni}_{0.5} \mathrm{Fe}_{2} \mathrm{O}$ nanopowder is not affected by the type of fuel, as a reducing agent. The coercivity of a magnetic material is roughly a measure of its magnetocrystalline anisotropy [22] Cobalt ferrite usually forms an inverse spinel structure with very high anisotropy energy constants ( $\mathrm{K} 1$ and $\mathrm{K} 2$ ). As the $\mathrm{Co}^{2+}$ is substituted by $\mathrm{Ni}^{2+}$, the antiferromagnetic interaction decreases and the ferromagnetic superexchange interaction increases which leads to a decrease in coercivity and reduction of magnetization [22]. So, the coercivity of the samples is lower than the one measured in other investigations [6, 26, 28]. The $\mathrm{H}_{C}$ value obtained in this research is lower than the value of cobalt-nickel ferrite nanoparticles synthesized via double layer hydroxide precursor method [3], co-precipitation [4] and the microwave combustion [5].

$\mathrm{M}_{\mathrm{s}}$ values for the samples that were synthesized with citric acid, glycine and urea fuels are 63.91, 63.72 and $59.23(\mathrm{emu} / \mathrm{g})$, respectively. $\mathrm{M}_{\mathrm{S}}$
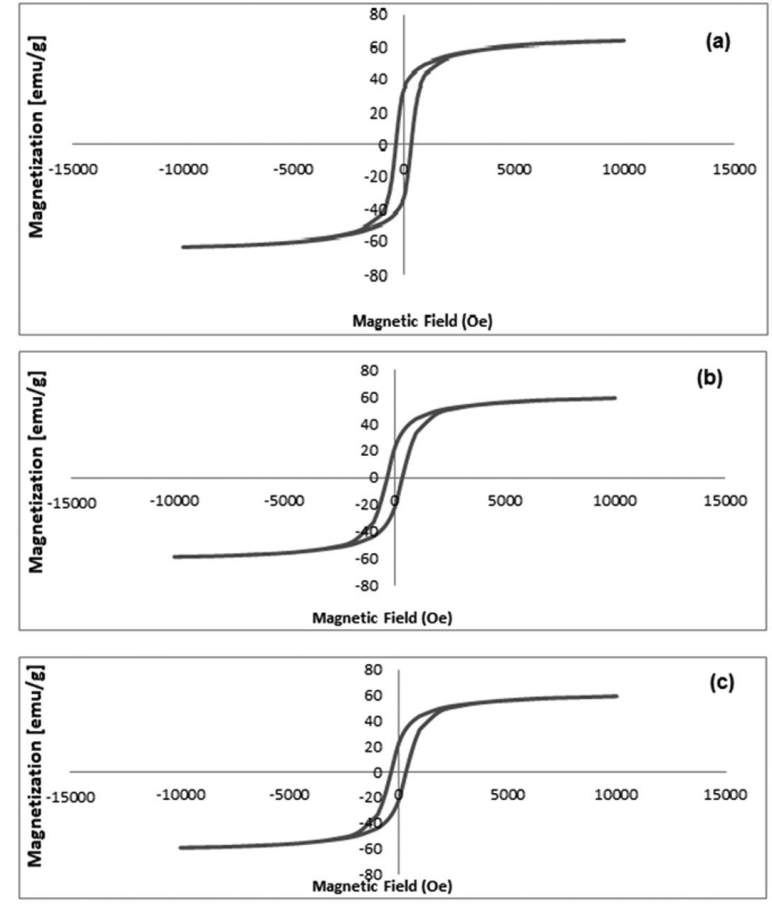

Fig. 7. Magnetic hysteresis loops of $\mathrm{Ni}_{0.5} \mathrm{Co}_{0.5} \mathrm{Fe}_{2} \mathrm{O}_{4}$ nanopowders synthesized with (a) citric acid, (b) glycine, (c) urea fuels

values in the samples that were synthesized with citric acid and glycine fuels are higher than the values obtained by a double layer hydroxide precursor method [3], co-precipitation [4], sol-gel [5] and aerosol [14] but in the samples of urea, the $M_{s}$ value is less than the value for samples synthesized by aerosol. It is easy to deduce that the evolution behavior of $\mathrm{M}_{\mathrm{s}}$ and $\mathrm{M}_{\mathrm{r}}$ highly depends upon the growth of $\mathrm{Co}_{0.5} \mathrm{Ni}_{0.5} \mathrm{Fe}_{2} \mathrm{O}_{4}$ nanocrystallites. Because both the remarkable changes in $\mathrm{M}_{\mathrm{s}}$ and $\mathrm{M}_{\mathrm{r}}$ and the average crystallite size occur due to fuel treatment, so using of different fuels changes the magnetic properties of the nanopowders. From 
previous research results [6] it is obvious that magnetic properties of $\mathrm{Co}_{0.5} \mathrm{Ni}_{0.5} \mathrm{Fe}_{2} \mathrm{O}_{4}$ nanoparticles depend upon adopted adiabatic flame temperature during combustion reaction. Also the dependence of the magnetization and magnetic moment on the grain size has been explained previously on the basis of changes in exchange interaction between tetrahedral and octahedral sub-lattices [26]. It can be seen that in the nanopowders synthesized with citric acid and glycine fuels, the sample with smaller grain size has less saturation magnetization, so this corresponds to the results of previous studies $[6,26]$. It was expected that the maximum saturation magnetization would occur in the samples synthesized with urea because of the biggest crystallite size, but this phenomenon was not observed experimentally. This observation may be due to three factors:

1. The presence of anti-ferromagnetic $\mathrm{Fe}_{2} \mathrm{O}_{3}$ phase, may contribute to the reduction in magnetization [26].

2. Both the saturation magnetization $\left(\mathrm{M}_{\mathrm{s}}\right)$ and the remnant magnetization $\left(\mathrm{M}_{r}\right)$ were found to be highly dependent upon the size and crystallinity of the investigated ferrite. From XRD results it is clear that the samples synthesized with urea have lower diffraction peak height than the others.

3. The low magnetization value observed in the samples fabricated with urea fuel may be due to wide particle size distribution, which leads to reducing magnetization [26].

The value of remanence ratios are close to those expected (0.5) for a system of non-interacting single domain particles with uniaxial anisotropy [19]. The existence of an effective uniaxial anisotropy in magnetic nanoparticles has been attributed to surface effects $[20,21]$ as evidenced by simulations of nanoparticles.

\section{Conclusions}

1. Formation of pure and single phase crystalline $\mathrm{Ni}_{0.5} \mathrm{Co}_{0.5} \mathrm{Fe}_{2} \mathrm{O}_{4}$ ferrites is feasible by gel combustion method but using urea as
Table 4. Comparison of saturation magnetization $\left(\mathrm{M}_{\mathrm{s}}\right)$; coercivity $\left(\mathrm{H}_{\mathrm{c}}\right)$; remnant magnetization $\left(\mathrm{M}_{\mathrm{r}}\right)$ between $\mathrm{Ni}_{0.5} \mathrm{Co}_{0.5} \mathrm{Fe}_{2} \mathrm{O}_{4}$ and loop squareness ratios $\mathrm{M}_{\mathrm{r}} / \mathrm{M}_{\mathrm{s}}$.

\begin{tabular}{ccccc}
\hline Fuel & $\mathrm{M}_{\mathrm{r}} / \mathrm{M}_{\mathrm{s}}$ & $\mathrm{M}_{\mathrm{r}}[\mathrm{emu} / \mathrm{g}]$ & $\mathrm{M}_{\mathrm{s}}[\mathrm{emu} / \mathrm{g}]$ & $\mathrm{H}_{\mathrm{c}}(\mathrm{Oe})$ \\
\hline \hline Citric acid & 0.52 & 33.44 & 63.91 & 300 \\
Glycine & 0.47 & 30.24 & 63.72 & 300 \\
Urea & 0.37 & 21.92 & 63.85 & 300 \\
\hline
\end{tabular}

a fuel forming traces of secondary hematite in the fabricated samples which is not favorable.

2. $\mathrm{Ni}_{0.5} \mathrm{Co}_{0.5} \mathrm{Fe}_{2} \mathrm{O}_{4}$ nanoparticles synthesized by gel combustion method have various crystallite sizes depending on fuel type which controls exothermic redox reaction between nitrate ions and fuel.

3. According to thermodynamic calculations and thermal analysis results, it is found that strong and sharp exothermic peaks appear when using citric acid and glycine fuels, but when using urea as a fuel, it is not possible to provide enough combustion energy for completing reaction. X-ray diffraction patterns of the samples confirm this prediction showing impurity in the samples fabricated with urea fuels.

4. The study of the samples structure by SEM shows large and homogeneous grains with agglomerated and porous structure due to the release of large amounts of gases during combustion.

5. The study of the samples magnetic properties shows that $\mathrm{M}_{\mathrm{s}}$ and $\mathrm{M}_{\mathrm{r}}$ are highly dependent upon the growth of $\mathrm{Co}_{0.5} \mathrm{Ni}_{0.5} \mathrm{Fe}_{2} \mathrm{O}_{4}$ nanocrystallites but fuel type does not change coercivity $\left(\mathrm{H}_{\mathrm{c}}\right)$ of the samples.

\section{References}

[1] Bhattacharyya S., Salvetat J., Fleurier R., Husmann A., CacciaguerraA T., SABounGIA M., J. Chem. Commun., (2005), 4818.

[2] Shobana M.K., Sankar S., J. Magnetism and Magnetic Materials., 321 (2009), 3132.

[3] Yonglian QI., Yingsheng Y., Zhao X., Xilan L., Peng W., FAZhi Z., SAilong X., J. Particuology., 8 (2010), 207. 
[4] Mathe V.L., Sheikh A.D., J. Physica., 405 (2010), 3594.

[5] ZHANG C.S., J. Magnetism and Magnetic Materials., 324 (2012), 1469.

[6] Deraz N.M., J. Analytical and Applied Pyrolysis., 88 (2010), 103.

[7] El-OKR M.M., SAlEM M.A., SAlim M.S., El-OKR R.M., Ashoushet M., TalaAt H.M., J. Magnetism and Magnetic Materials., 323 (2011), 920.

[8] Ahlawat A., Reddy V.R., Gupta A., J. Magnetism and Magnetic Materials., 323 (2011), 2049.

[9] ZhenXing Y., Wenyu G., Ji Z., Zhilun G., Logtu L., J. Magnetism and Magnetic Materials., 270 (2004), 216.

[10] Deganello F., Mard G., Deganello G., J. the European Ceramic Society., 29 (2009), 439.

[11] PUi A., Gherca D., CARJA G., J. Nanomaterials and Biostructures., Vol. 6, No 4, (2011), 1783.

[12] Shelar M.B., Jadhav P.A., Chougule S.S., MalLApur M.M., Chougule B.K., J. Alloys and Compounds., 476 (2009), 760.

[13] Waje S., Hashim M., Ismail I., J. Magnetism and Magnetic Materials., 323 (2011), 1433.

[14] Singhal S., Singh J., Barthwai S.K., ChanDRA K., J. Solid State Chemistry., 178 (2005), 3183.

[15] LeZhong L., Long P., YuAnXUn L. Xinghua Z., J. Magnetism and Magnetic Materials., 324 (2012), 60.

[16] Wu K.H., Ting T.H., Li M.C., Ho W.D., J. Magnetism and Magnetic Materials., 298 (2006), 25.

[17] Costa A., Silva V., Xin C., Vieira D., Cornejo D., Kiminami R., J. Alloys and Compounds., 495 (2010), 503.
[18] Prabhakaran T., Hemalatha J., J. Alloys and Compounds., 509 (2011), 7071.

[19] Gonsalves L., Mojumdar S., Verenkar V., J. Thermal Analysis and Calorimetry., (2010), 789.

[20] Bahadur D., Rajakumar S., Kumar A., J. Chemical Science., Vol. 118, No. 1, (2006), 15.

[21] Ramalho M.A.F., Gama L., Antonio S.G., Paiva Santos C.O., Miola E.J., Kiminami R.H.G.A., J. Material Science., (2007), 3603.

[22] Baykal A., Kasapoglu N., Koseoglu Y., Basaran A., Kavas H., Toprak M., J. Chemistry, 6(1) (2008), 125.

[23] Costa A.C.F.M., Morelli M.R., Kiminami R.H.G.A., J. Materials Synthesis and Processing., (2001), 347.

[24] Costa A.C.F.M., Lula R.T., Kiminami R.H.G.A., GAmA L.F.V., DE Jesus A.A., ANDRAdE H.M.C., $J$. Material Science, (2006), 4871.

[25] Waje S., Hashim M., Yusoff W., Daud W., AвBAS Z., J. nanoparticle., 25 (2011), 1225.

[26] Salunkhe A.B., Khot V.M., Phadatare M.R., PAWAR S.H., J. Alloys and Compounds., 514 (2012), 91.

[27] JAKUBOVICS J.P., Magnetism and Magnetic Materials, Brookfield, London, 1987.

[28] Toksha B.G., Shirsath S., Patange S., JaDHAV K., J Solid State Communications., 147 (2008), 479 .

Received 2018-10-16 Accepted 2019-08-28 